\title{
PRIMEROS ESTUDIOS SOBRE LA COMPOSICIÓN ESPECTRAL DE LA LUZ Y SU RELACIÓN CON ILAS POBLACIONES DE BACTERIAS FOTOTRÓFICAS DEL AZUFRE EN LA CUENCA LACUSTRE DE BANYOLES (GIRONA).
}

X. Vila, J.B. Figueras y C.A. Abella

Institut d'Ecologia Aquàtica, Universitat de Girona, Pl. Hospital, 6, 17071 Girona

Palabras clave : bacterias fototroficas del azufre, competencia por la luz, composición espectral de la luz, Banyoles.

\section{ABSTRACT}

The spectral composition of light has been studied in several ponds and basins of the lake Banyoles area, using an underwater spectroradiometer. Different spectra are attributed to different phototrophic organisms present in the water. Therefore, it has been possible to identify the ranges of the spectrum in which water and dissolved substances, phytoplankton and different groups of phototrophic bacteria absorve light. The results evidence that spectral composition of light and absorption differences among these groups are important factors in the resolution of their competence for light.

\section{INTTRODUCCIÓN}

La zona lacustre de Banyoles (Girona), de origen cárstico, está formada por el lago de Banyoles, compuesto a su vez por un conjunto heterogéneo de cubetas, y varias lagunas de características muy distintas entre si. Se han descrito poblaciones de bacterias fototroficas del azufre en muchas lagunas y cubetas de esta zona (Abellà, 1980), en algunos casos con comunidades formadas por varias especies, superpuestas o compitiendo entre ellas a un mismo nivel. En esta competencia parecen jugar un papel importante las características espectrales de la luz y las diferencias entre las zonas de absorción de los grupos de bacterias fototróficas con distintos pigmentos captadores de luz (Abellà et al., 1980; Parkin y Brock, 1980; Montesinos, 1982; Montesinos et al., 1983).

En este trabajo se ha estudiado la composición espectral de la luz en varias lagunas y cubetas del lago principal, utilizando un espectrorradiómetro sumergible (Kirk, 1983). Los diferentes espectros obtenidos según el lugar y la época del año se han podido relacionar con los organismos fotosintéticos presentes en la columna de agua, permitiendo identificar las zonas de absorción de luz correspondientes a cada uno de los grupos.

\section{MATERIAL Y MÉTODOS}

Los puntos de muestreo que se utilizaron para este estudio, pertenecientes a la cuenca lacustre de Banyoles, son los siguientes (figura 1) : las cubetas III y IV del lago de Banyoles, la cubeta II de la laguna Vilar y las lagunas Sisó y Nou.

En todos ellos se realizaron perfiles verticales de temperatura, conductividad (ambos parámetros medidos con un conductivímetro WTW modelo LF 191), oxígeno disuelto (con un oximetro Yellow Spring Instruments modelo 57) y potencial Red-Ox (con un electrodo combinado de platino METROM 6.0401.100), y se calcularon las concentraciones de clorofilas y bacterioclorofilas, mediante filtración y extracción en 


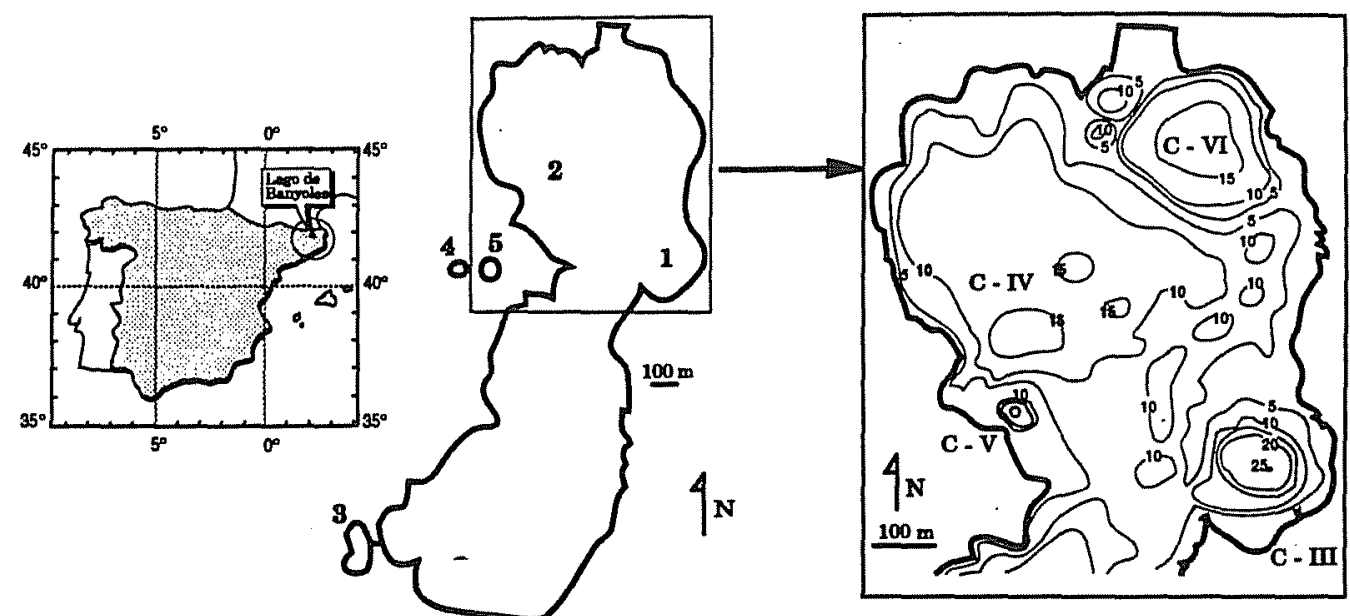

Figura 1.L̃ocalización geográfica del lago de Banyoles y mapa batimétrico del lobulo norte del mismo donde se muestran las diferentes cubetas que lo componen. Los números indican los puntos de muestreo : (1) Banyoles III; (2) Banyoles IV; (3) Vilar II; (4) Sisó; (5) Nou.

acetona (Smith y Benítez, 1955; Humphrey y Wooton, 1966; Takahashi y Ichimura, 1968, 1970; Montesinos, 1982), utilizando un espectrofotómetro Milton Roy Spectronic 3000 Array. Con un espectrorradiómetro sumergible LI-1800 UW (LI-COR) se analizó la composición espectral (entre 300 y $850 \mathrm{~nm}$, con lectura cada $2 \mathrm{~nm}$ ) de la luz incidente a distintas profundidades, calculándose también los valores de PAR (Photosynthetic Active Radiation, radiación integrada entre 400 y $700 \mathrm{~nm}$ ).

La evaluación de estos parámetros tuvo lugar en distintos momentos del ciclo estacional, con lo que se pudieron analizar también las variaciones en las condiciones de luz a lo largo del año, además de las diferencias entre los puntos de muestreo.

\section{RESULTADOS Y DISCUSIÓN}

Los resultados de algunos de los perfiles se presentan en las figuras 2 y 3 . Se han seleccionado aquellos muestreos entre los cuales los espectros lumínicos son más distintos, siendo por tanto representativos de las distintas condiciones de luz que se presentan a lo largo del año en las cubetas y lagunas de la cuenca lacustre. Un resumen comparativo de estos mismos resultados se ofrece en la tabla 1.

En Banyoles III, a 28-1-91, las concentraciones de Clor $a$ eran muy bajas, por lo que la extinción de luz era debida mayoritariamente al agua y las partículas inorgánicas que contiene. Afectaba principalmente a los dos extremos del espectro, dejando un móximo de transmisión de luz a $530 \mathrm{~nm}$. En Vilar II, a 3-4-91, existía además una importante absorción entre 500 y $550 \mathrm{~nm}$ que puede relacionarse con el desarrollo de poblaciones importantes de fitoplancton (Clor $a$ en concentraciones de 8-15 $\mu \mathrm{g} . \mathrm{l}^{-1}$ ) y que se manifestaba desplazando el máximo de transmisión hasta $570 \mathrm{~nm}$. Una pequeña banda de absorción entre 670 y $680 \mathrm{~nm}$ era debida también a las algas, el espectro de acción de las cuales presenta un máximo de absorción en esta zona. 


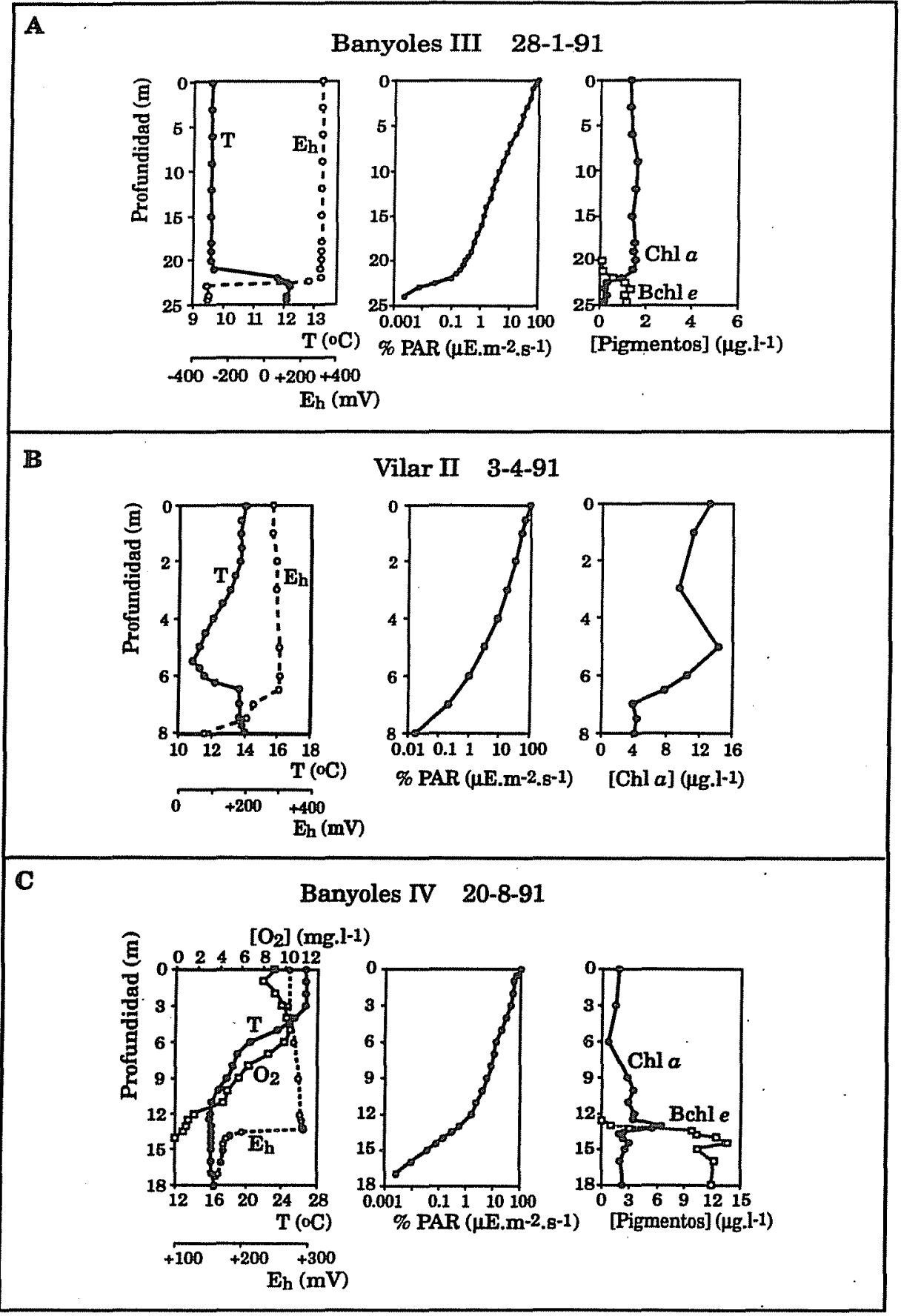

Fig. 2 (a). Principales parámetros físico-químicos y concentraciones de pigmentos fotosintéticos de las cubetas III y IV del lago de Banyoles y la cubeta II de la laguna Vilar en los días en que se realizaron los muestreos. 


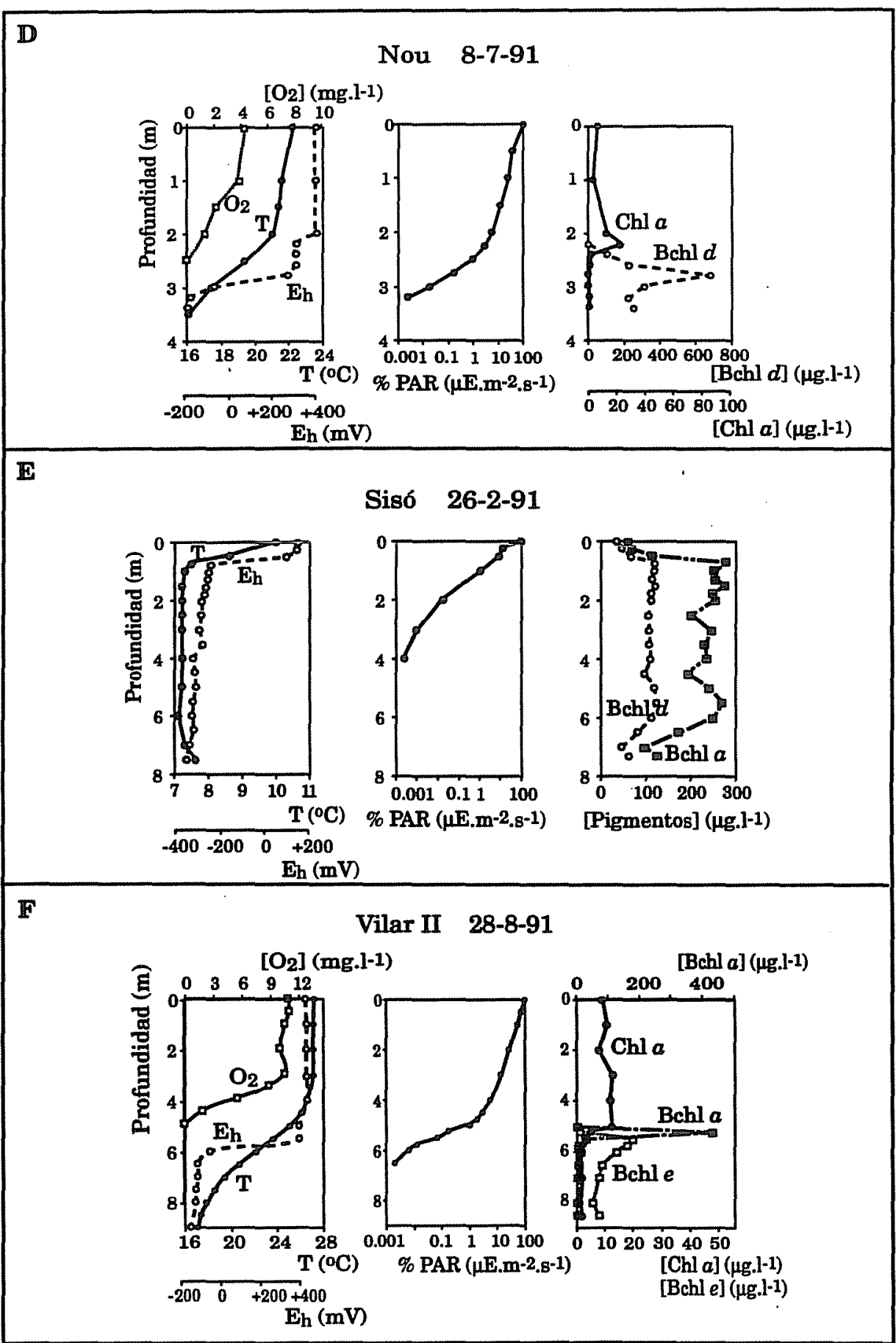

Fig. 2 (b). Principales parámetros físico-químicos y concentraciones de pigmentos fotosintéticos de las lagunas Nou y Sisó y la cubeta II de la laguna Vilar en los días en que se realizaron los muestreos. 
Banyoles III 28-1-91

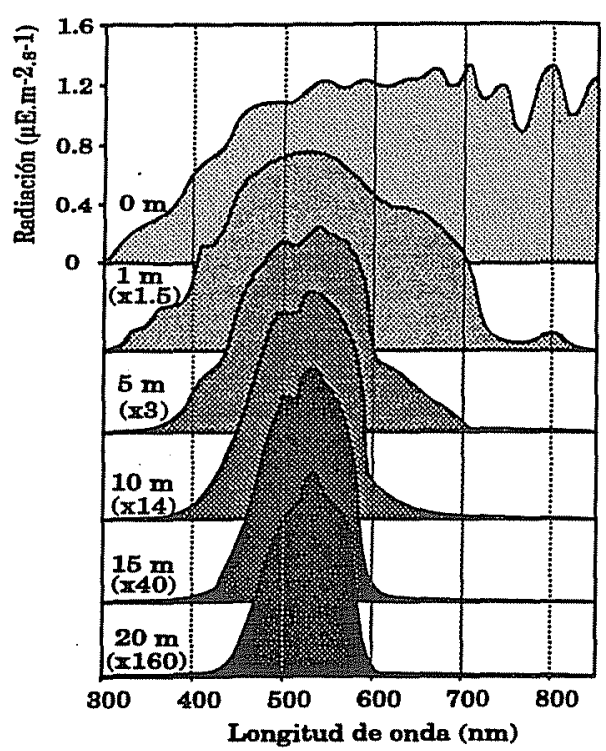

Banyoles IV 20-8-91

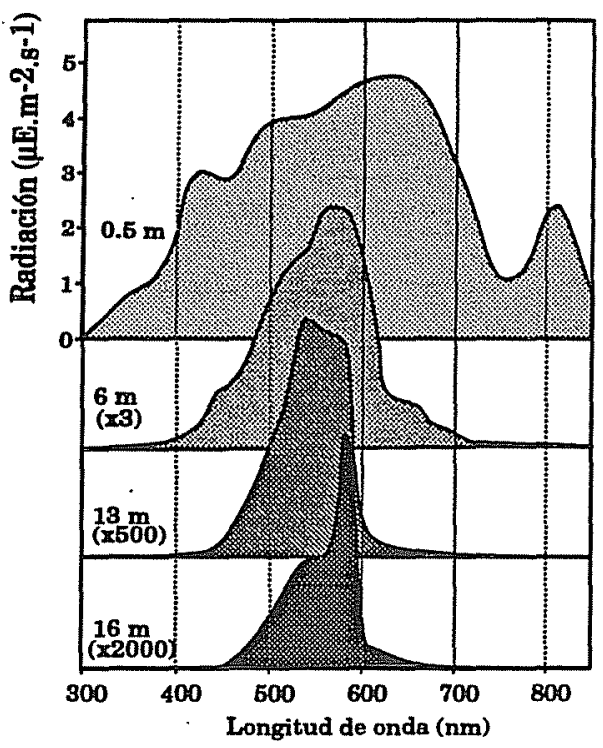

Vilar II 3-4-91

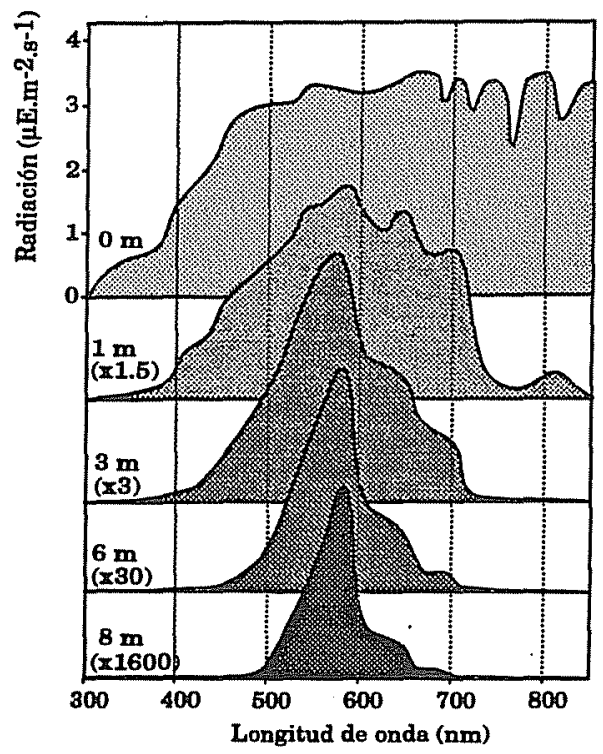

Nou $8-7-91$

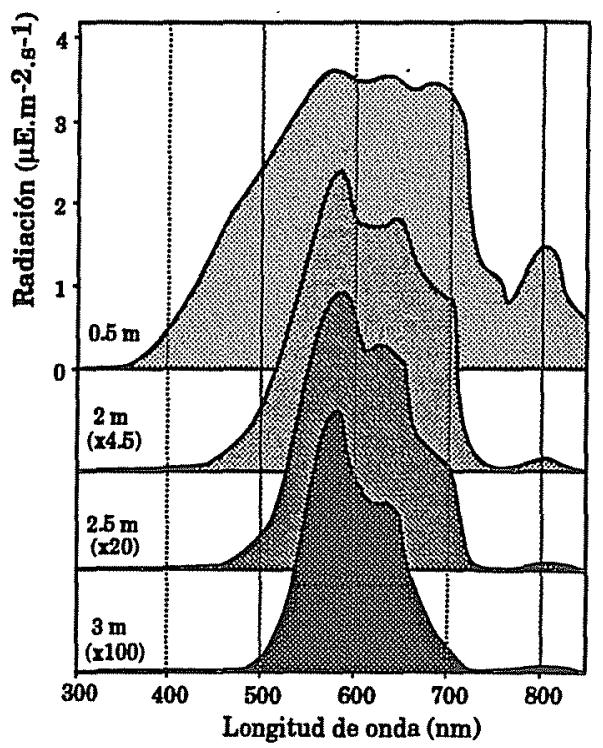

Fig. 3 (a). Composición espectral de la luz a distintas profundidades en la laguna Nou, las cubetas III y IV del lago de Banyoles y la cubeta II de la laguna Vilar. Las gráficas representan la luz incidente para cada longitud de onda, en $\mu \mathrm{E} \cdot \mathrm{m}^{-2} . \mathrm{s}^{-1}$. Para cada profundidad se indica, entre paréntesis, el factor de proporcionalidad de su espectro respecto de la escala representada en el margen superior izquierdo del perfil. 

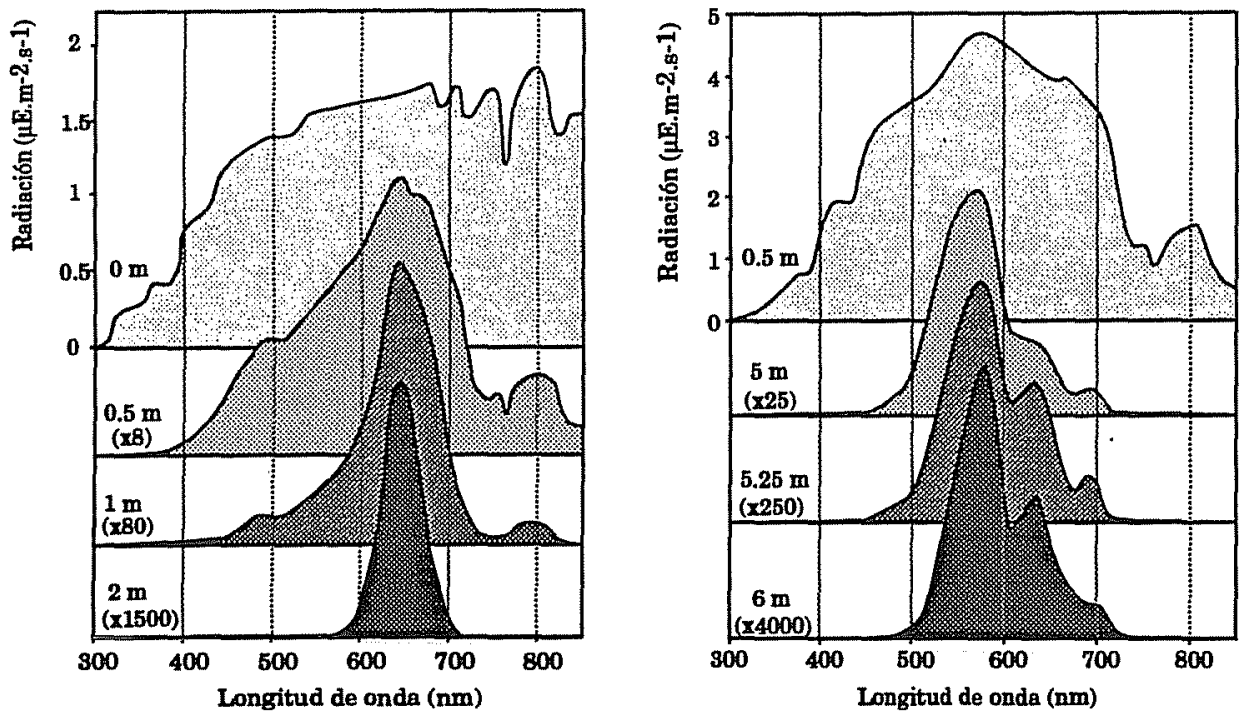

Fig. 3 (b). Composición espectral de la luz a distintas profundidades en la laguna Sisó y la cubeta II de la laguna Vilar. Las gráficas representan la luz incidente para cada longitud de onda, en $\mu E, m-{ }^{2} . s^{-1}$. Para cada profundidad se indica, entre paréntesis, el factor de proporcionalidad de su espectro respecto de la escala representada en el margen superior izquierdo del perfil.

En el fondo de la cubeta IV del lago de Banyoles, a 20-8-91, tenía lugar una intensa absorción de la luz entre 550 y $570 \mathrm{~nm}$, desplazando el máximo hasta $580 \mathrm{~nm}$. En este caso, las poblaciones de organismos fotosintéticos que se encontraban a estas profundidades eran de bacterias fototroficas marrones del azufre (Chlorobium phaeobacteroides, con concentraciones de Bclor $e$ de 10-12 $\mu \mathrm{g} . \mathrm{l}^{-1}$ ). En Nou (8-7-91), sin embargo, el efecto de las bacterias fototróficas verdes (Pelochromatium aggregatum) del fondo, con concentraciones de Bclor $d$ alrededor de $700 \mu \mathrm{g} . \mathrm{l}^{-1}$, no diferia del que producian las algas que se encontraban en las capas superiores de la misma laguna o en la cubeta II del Vilar.

La laguna Sisó presentaba, a 26-2-91, una mezcla de poblaciones de bacterias fototr6ficas verdes (Chlorobium limicola, con Bclor d) y púrpuras (Lamprocystis sp. y Chromatium sp., con Bclor a), cuyo efecto combinado sobre el espectro de luz era una absorción muy fuerte por debajo de $620 \mathrm{~nm}$, quedando relegado el máximo de transmisión de luz a $630 \mathrm{~nm}$. La absorción de las bacterias púrpuras debía manifestarse, pues, alrededor de $600 \mathrm{~nm}$. Los espectros lumínicos de Vilar II a 28-8-91 permiteron definir mejor la banda de absorción de las bacterias púrpuras, que se desarrollaban entre 5 y 5.5 $m$ de profundidad, debajo de una capa considerable de algas y por encima de las bacterias fototróficas marrones (Chlorobium phaeobacteroides). Sus efectos se producían entre 580 y $620 \mathrm{~nm}$, dejando máximos de transmisión de luz a 570 y $630 \mathrm{~nm}$, respectivamente.

A partir de estos resultados se ha elaborado el modelo idealizado de la figura 4, en el que se indican las zonas del espectro de máxima absorción de luz para cada grupo de organismos fototróficos (algas y bacterias fototróficas del azufre verdes, marrones y púrpuras), así como las zonas en que la extinción de laluz es debida al agua y las partículas inorgánicas que contiene, y sus variaciones con la profundidad. 
Tabla 1. Resumen comparativo de los resultados obtenidos en los distintos muestreos.

\begin{tabular}{|c|c|c|c|c|c|}
\hline $\begin{array}{c}\text { Nombre del } \\
\text { lago o } \\
\text { laguna }\end{array}$ & $\begin{array}{c}\text { Fecha de } \\
\text { realización } \\
\text { del perfil }\end{array}$ & $\begin{array}{c}\text { Presencia } \\
\text { de algas } \\
\text { ([Clor a] } \\
\left.\text { en } \mu \mathrm{g} \cdot \mathrm{I}^{-1}\right)\end{array}$ & $\begin{array}{c}\text { Presencia de } \\
\text { bacterias } \\
\text { fototróficas } \\
\left([\mathrm{Bcl}] \text { en } \mu \mathrm{g} \cdot \mathrm{l}^{-1}\right)\end{array}$ & $\begin{array}{c}\text { Zonas de } \\
\text { absorción de } \\
\text { luz en el } \\
\text { espectro (nm) }\end{array}$ & $\begin{array}{c}\text { Máximo(s) de } \\
\text { transmisión } \\
\text { de la luz } \\
(\mathrm{nm})\end{array}$ \\
\hline Banyoles III & 28/1/91 & $<2$ & $<2$ & $\begin{array}{l}300-450 \\
650-850\end{array}$ & 530 \\
\hline Vilar II & $3 / 4 / 91$ & $8-15$ & 0 & $\begin{array}{l}300-550 \\
650-850\end{array}$ & 570 \\
\hline Banyoles IV & 20/8/91 & $2-6$ & $\underset{10-12}{\text { Marrones }}(\mathrm{Bcl} e)$ & $\begin{array}{l}300-570 \\
650-850\end{array}$ & 580 \\
\hline Nou & 7/8/91 & $5-20$ & $\begin{array}{l}\text { Verdes }(\mathrm{Bcl} d) \\
700\end{array}$ & $\begin{array}{l}300-550 \\
650-850\end{array}$ & 570 \\
\hline Siв 6 & $26 / 2 / 91$ & 0 & $\begin{array}{l}\text { Purpuras (Bcl a) } 250 \\
\text { Verdes (Bcl } d) \\
100\end{array}$ & $\begin{array}{l}300-620 \\
650-850\end{array}$ & 630 \\
\hline Vilar II & $28 / 8 / 91$ & 8-12 & $\begin{array}{l}\text { Purpuras (Bcl a) } 450 \\
\text { Marrones (Bcl e) } 20\end{array}$ & $\begin{array}{l}300-650 \\
580-620 \\
650-850\end{array}$ & $\begin{array}{l}570 \\
630\end{array}$ \\
\hline
\end{tabular}
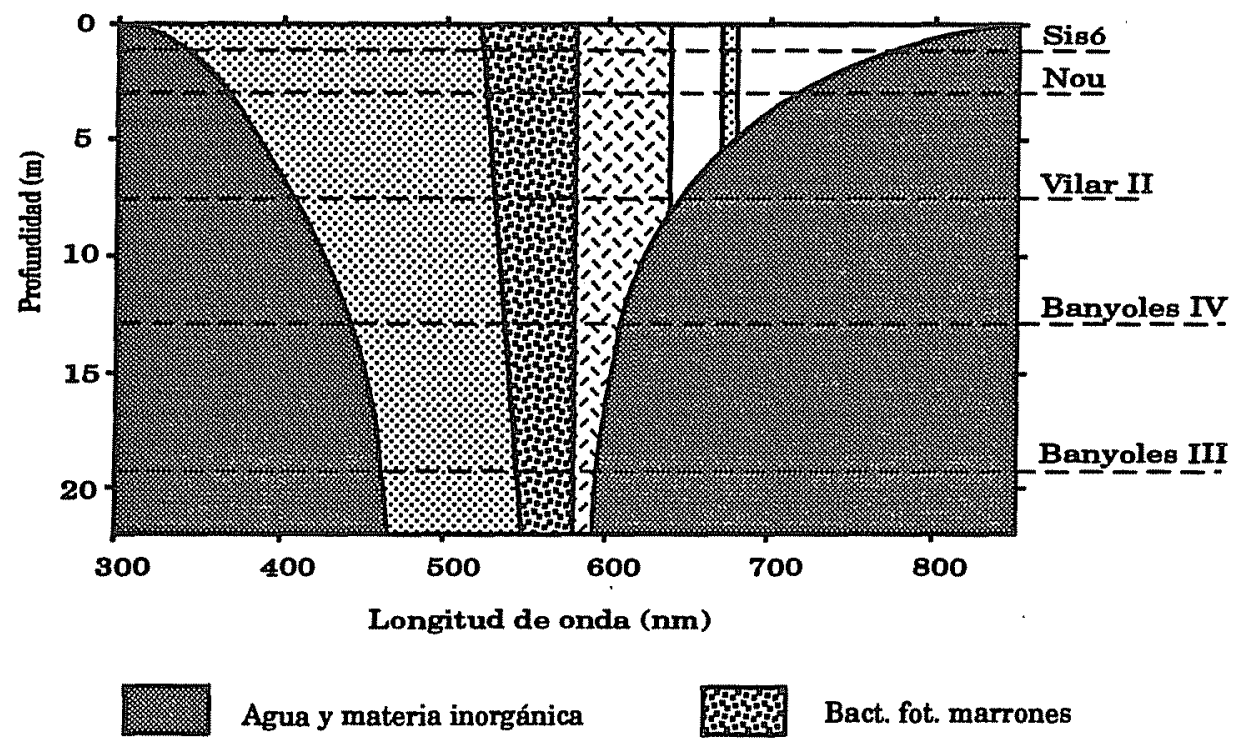

Agua y materia inorgánica

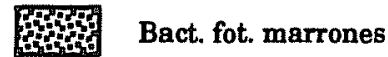

33 Algas y bact. fot. verdes

Bact. fot. púrpuras

Fig. 4. Modelo idealizado de absorción de la luz en la columna de agua. Se indican, para las distintas profundidades, las zonas del espectro lumínico que se ven afectadas por los distintos elementos que intervienen en la extinción de la luz. Las líneas de puntos representan las profundidades a las que suelen desarrollarse las poblaciones de bacterias fototróficas en las cubetas y lagunas estudiadas. 


\section{CONCLUSIONES}

El agua y las partículas inorgánicas son las responsables de la fuerte disminución de la luz que se produce por encima de $700 \mathrm{~nm}$. Por debajo de $450 \mathrm{~nm}$ y entre 600 y $700 \mathrm{~nm}$ sus efectos se ponen también de manifiesto, aunque con una menor intensidad.

Las poblaciones planctónicas de algas absorben fuertemente por debajo de $550 \mathrm{~nm}$ y tienen también una pequeña banda de absorción de luz entre 670 y $680 \mathrm{~nm}$.

Las bacterias fototróficas verdes utilizan también la luz de longitudes de onda inferiores a $550 \mathrm{~nm}$. Su desarrollo a grandes profundidades y bajo poblaciones algales densas puede verse limitado por la superposición de su zona de absorción del espectro con las de las algas, el agua y las partículas inorgánicas.

Las bacterias fototróficas marrones inciden en el espectro lumínico de forma parecida a las algas y bacterias fototróficas verdes, pero presentan una absorción más fuerte en la zona de 550-570 $\mathrm{nm}$. Esto puede representarles una ventaja en la competencia por la luz con las bacterias verdes, especialmente en las condiciones comentadas en el punto anterior.

Las bacterias fototróficas púrpuras realizan la absorción de luz principalmente entre 580 y $620 \mathrm{~nm}$. Pueden permitir, por tanto, el desarrollo a mayores profundidades de poblaciones de organismos fotosintéticos que aprovechen las bandas del espectro (o ventanas de luz) que ellas no utilizan y su crecimiento no se ve tampoco desfavorecido por el desarrollo de algas en las capas superiores.

\section{BIBLIOGRAFÍA}

Abellà, C., 1980. Dinámica comparada de bacterias fotosintéticas planctónicas. Tesis doctoral, U.A.B.

Abellà, C., E. Montesinos y R. Guerrero, 1980. Field studies on the competition between purple and green sulfur bacteria for available light (Lake Siso, Spain). Developments in Hydrobiology, 3:173-181.

Humphrey, G.F. y M. Wooton, 1966. Comparison techniques used in the determination of phytoplankton pigments. Report SCOR-UNESCO. París.

Kirk, J.T.O., 1983. Light and photosynthesis in aquatic ecosystems. Cambridge University Press, New York.

Montesinos, E., 1982. Ecofisiologia de la fotosintesis bacteriana. Tesis doctoral, U.A.B.

Montesinos, E., R. Guerrero, C. Abellà y I. Esteve, 1983. Ecology and physiology of the competition for light between Chlorobium limicola and Chlorobium phaeobacteroides in natural habitats. Appl. Environ. Micorbiol. 46:1007-1016.

Parkin, T. B. y T. D. Brock, 1980. The effects of light quality on the growth of phototrophic bacteria in lakes. Arch. Microbiol. 125:19-27.

Smith, J.H. y A. Benitez, 1955. Chlorophylls. Analysis in plant materials. En : Modern methods of plant analysis. VH Springer-Verlag, Heidelberg.

Takahashi, M. y S. Ichimura, 1968. Vertical distribution and organic matter production of phototrophic sulfur bacteria in Japanese lakes. Limnol. Oceanogr._13:644-653.

Takahashi, M. y S. Ichimura, 1970. Photosynthetic properties and growth of photosynthetic sulfur bacteria in lakes. Limnol. Oceanogr. 15:924-944. 